in 1965. In a subject developing as quickly as this one, a book four years old is severely handicapped.

The chief emphasis in the book is on the experimental investigation, together with interpretation, of the transport properties of heavily doped semiconductors. Fistul' has published many papers on this subject and he gives an excellent and detailed account. It is, however, largely restricted to conduction in the valence and conduction bands in silicon and germanium and this topic occupies nearly a half of the book. The remainder is made up of two introductory chapters. The first chapter contains many mistakes; for example, the definition of the light and heavy hole masses is inconsistent, and some of the data quoted were obsolete in 1965 , but this is not at all representative of the remainder of the book. There is a chapter by Mil'vidski on the preparation of heavily doped semiconductors and a final chapter on some of the applications of heavily doped semiconductors.

The price of this book, the somewhat restricted treatment of the subject and the fact that it is dated mean that I can only recommend it for specialist libraries and laboratories.

R. MAnsfielid

\section{SEMICONDUCTORS IN THE MELT}

\section{Liquid Semiconductors}

By V. M. Glazov, S. N. Chizhevskaya, and N. N. Glagoleva. Translated from the Russian by Albin Tybulewicz. (Monographs in Semiconductor Physics, Vol. 2.) Pp. xii 362. (Plonum: New York, 1969.) \$22.50.

THE material covered in this book extends over a much wider field than the concise title suggests and the authors clearly appreciate that this may lead to misunderstanding, as they mention in the preface. Their concern is specifically with the temperature dependence of the important physical properties of those substances which exhibit semiconducting behaviour in the solid state. They then trace the changes which occur in these properties at the melting point and subsequently with further increase of temperature in the liquid phase.

The text is a research monograph rather than a textbook and, as such, it is the first monograph to appear on the subject of liquid semiconductors. Although the emphasis is on the properties of semiconductors in the melt, the collated information on the structure and chemical binding of the various classes of semiconducting solids is of general interest. A considerable proportion of the material presented is based on the results of the authors' own research, but for this they need make no apology because their work in this field has been considerable. The result, however, is that experimental data are presented somewhat uncritically, and the captions to many of the figures leave important details unstated which, nevertheless, are to be found on perusal of the text.

The chapter describing methods of measurement is based almost entirely on techniques which have been developed by the authors and is particularly valuable because of this. The measurement of electrical conductivity in the melt using an electrodeless method based upon a rotating magnetic field is ingenious. The assignment of semiconducting or metallic behaviour to a melt is made principally on the evidence provided by the absolute value and the variation with temperature of the electrical conductivity. Supporting evidence is then provided by measurements of the density, thermoelectric power, Hall coefficient and magnetic susceptibility as functions of temperature. Some semiconducting solids such as germanium, silicon, indium and gallium antimonide exhibit metallic behaviour in the liquid phase and their properties are discussed in detail. Other semiconductors such as zinc and cadmium telluride constitute the true liquid semiconductors which retain their semiconducting properties in the melt in the absence of long-range order.
Many useful data are presented in this text, and these include results of the variation with composition of the viscosity of binary liquid systems. Tables at the end of the book record numerical data on viscosity, density, electrical conductivity and thermoelectric power. Plainly, this book should serve as a useful library source of data for reference rather than as an addition to one's personal library.

JoHN LATIB

\section{ALTERNATIVE TO KITTEL}

\section{Solid State Physics}

By J. S. Blakemore. Pp. xii +391. (Saunders: Philadelphia, June 1969.) 115s.

THis book will certainly be examined with interest by solid state physics teachers. There are relatively ferw advanced undergraduate textbooks on this topic: since 1953, Kittel's classic Introduction to Solid State Physics has dominated the field so effectively that few competitors have appeared, and the admirable third edition of 1966 has maintained this position. But Kittel's book is of somewhat forbidding length, and a rather shorter and less detailed text would bo a usoful alternative.

The present book, though very similar in price to Kittel's, is only about three-fifths of the length, and thus offers such an alternative. It is divided into five long chapters, on erystal structure, lattice dynamics, electrons in metals, semiconductors and dielectric and magnetic properties. The first chapter starts off, a little unpromisingly, with a garbled account of van der Waals forees on page 5 and an erroneous piece of etymology on page 7 , but after these initial blemishes the author settles down to a generally orthodox and readable account of the traditional topics, in more or loss tho traditional order.

The chapter on electrons in metals, which is the longest in the book (115 pages), starts off for some reason with at ten-page survey of the classical Drude-Lorentz theory, which might perhaps have been compressed to make a little more room for superconductivity at the end of the chapter: the attempt to cover the whole of this topic in fifteen pages is inevitably not very successful. Similarly, the rather detailed treatment of all the ramifications of semiconductor statistics might have been curtailed to make room for a more adequate treatment of dielectric and magnetic properties in the last chapter.

Taken as a whole, the book lacks the incisive clarity of Kittel, and for teaching honours physicists most people will almost certainly prefer Kittel. But for slightly less specialized audiences, this book may prove useful.

\section{R. G. Chambers}

\section{THINGS SYMMETRICAL}

\section{Crystals and their Structures}

By Arthur P. Cracknell. (The Commonwealth and International Library of Science, Technology, Engineering and Liberal Studies.) Pp. ix +231 . (Pergamon: Oxford, London and New York, July 1969.) 45s (\$7) boards; $35 s(\$ 5)$ paper.

THIS book is aimed at the sixth-former for background reading, and perhaps at some first-year university students. On reading this in the preface $I$ realized I was inappropriate as a reviewer unless I could cast my mind back successfully to those days. Indeed, it was in the sixth form that my interest in things symmetrical was stimulated by reading fairly deeply along some narrow lines, seeing some problems of interest but having time to investigate only a few thoroughly. At university, the need for a broad, careful and thorough study of the scientifically more important problems was indeed a complete contrast. To cover these contrasting aims is the impossible task of this book. 